\title{
VARIAÇÃO DA TEMPERATURA E DO TEOR DE ÁGUA DO CAFÉ EM SECADOR ROTATIVO USANDO LENHA E GLP COMO COMBUSTÍVEIS
}

\author{
CARLOS H. R. REINATO ${ }^{1}$, FLÁVIO M. BORÉM ${ }^{2}$
}

\begin{abstract}
RESUMO: O presente estudo foi realizado no Pólo de Tecnologia em Pós-Colheita de Café, na Universidade Federal de Lavras - MG. Seu objetivo foi estudar a distribuição da temperatura e do teor de água na direção radial do secador rotativo. Para a realização do teste, foram usados, concomitantemente, dois secadores da marca Pinhalense, com capacidade de $5.000 \mathrm{~kg}$ cada; em um secador usou-se lenha e no outro GLP, como combustíveis para o aquecimento do ar. A medição da temperatura do ar de secagem e da massa de café foi feita por meio de termopares distribuídos em 18 pontos no secador. As leituras de todas as temperaturas, registradas em um indicador, foram feitas em intervalos de meia hora. A redução do teor de água foi acompanhada em nove pontos na massa de café. Observou-se que os valores da temperatura no plenum apresentaram menor oscilação na secagem quando se usou o GLP. Além disso, independentemente do tipo de combustível, foram observados gradientes máximos de até $25^{\circ} \mathrm{C}$ na temperatura e três pontos percentuais no teor de água na direção radial, na seção central do secador, em razão dos maiores valores de pressão estática $(637,84 \mathrm{~Pa})$. De maneira geral, independentemente do combustível usado, o gradiente de temperatura observado longitudinalmente na massa de café foi bem menor do que na direção radial.
\end{abstract}

PALAVRAS-CHAVE: gradiente, secagem, Coffea arabica L.

\section{VARIATION OF THE TEMPERATURE AND MOISTURE CONTENT OF THE COFFEE IN HORIZONTAL DRYERS USING FIREWOOD E GLP AS FUEL}

\begin{abstract}
The present study was accomplished in the "Pólo de Tecnologia em Pós-Colheita de Café", at the "Universidade Federal de Lavras", MG, Brazil. Its objective was to investigate the distribution of temperature and moisture content in the radial direction of the rotary dryer. For the test accomplishment, two dryers of the Pinhalense mark were used concomitantly with a 5,000 kg capacity. In a dryer, firewood was used and in the other GLP, as fuels for air heating. The air drying and coffee mass temperature were determined by means of thermocouples distributed on eighteen ends of the dryer. The readings of all the temperatures recorded on the dial were done every half an hour. Moisture content loss was followed in nine points in coffee mass. It was found that the values of temperature in the plenum presented less oscillation in the drying which used GLP. Furthermore, regardless the sort of fuel, there were found maximum temperature gradient of $20{ }^{\circ} \mathrm{C}$ and three percents points of moisture content in the radial direction in central section, as consequence of the higher values of static pressure $(637.84 \mathrm{~Pa})$ in the plenum observed in this section. Regardless the kind of fuel, the temperature gradient measured in the longitudinal sense of the coffee mass was substantially less in the radial direction.
\end{abstract}

KEYWORDS: gradient, drying, Coffea arabica L.

\section{INTRODUÇÃO}

No processamento do café, a secagem poderá ser realizada completamente em terreiro ou associando-se esse a secadores mecânicos (LACERDA FILHO, 1986). A secagem mecânica com altas temperaturas, quando usada, é, sem dúvida, a etapa que mais consome energia. Entre outros fatores, a temperatura que a massa de café atinge durante a secagem é uma das principais causas

\footnotetext{
${ }^{1}$ Eng ${ }^{\mathrm{o}}$ Agrícola, Doutorando do curso de Ciências dos Alimentos, UFLA, Lavras - MG.

${ }^{2}$ Prof. Adjunto, Departamento de Engenharia, UFLA, Fone: (0XX35) 3829.1488, Lavras - MG.

Recebido pelo Conselho Editorial em: 21-9-2004

Aprovado pelo Conselho Editorial em: 24-5-2006
} 
para a depreciação da qualidade do produto. Entretanto, o uso de temperaturas elevadas tem sido largamente empregado como uma das maneiras de obter maior eficiência no processo de secagem pela redução tanto no tempo de secagem como no consumo de combustível. A recomendação técnica indica valores máximos de $40{ }^{\circ} \mathrm{C}$ para a secagem de café descascado e de $45^{\circ} \mathrm{C}$ para café em coco (CASTRO, 1991; GIRANDA, 1998; SILVA et al., 2000; OTAVIANI, 2000; REINATO et al., 2001).

No entanto, durante a secagem do café em secadores horizontais, o controle da temperatura máxima é realizado por meio de termômetros analógicos localizados na região de exaustão do ar, atingindo uma profundidade de apenas $10 \mathrm{~cm}$, não sendo possível controlar as condições de secagem em maiores profundidades. Os secadores horizontais podem apresentar profundidade radial de até $90 \mathrm{~cm}$, sem nenhuma caracterização das variações de temperatura e de teor de água da massa de café ao longo da secagem.

Considerando que tanto a temperatura como os gradientes de teor de água exercem grande influência na qualidade do café, este trabalho teve como objetivo caracterizar a distribuição da temperatura e do teor de água na direção radial do secador rotativo, usando lenha e GLP como combustíveis.

\section{MATERIAL E MÉTODOS}

O presente trabalho foi realizado no Pólo de Tecnologia em Pós-Colheita de Café, no Departamento de Ciência dos Alimentos e no Departamento de Engenharia, da Universidade Federal de Lavras - MG.

Para a obtenção da matéria-prima utilizada neste trabalho, foram colhidos $30.000 \mathrm{~kg}$ de café no setor de cafeicultura do Departamento de Agricultura da Universidade Federal de Lavras.

O café, com teor de água inicial de $55 \%$ b.u., foi derriçado manualmente sobre o pano e, em seguida, abanado, lavado e separado em função do seu estádio de maturação. Após a separação, a porção formada pelos frutos cereja e verde foi submetida à pré-secagem em terreiro.

Para realizar a pré-secagem, o café foi esparramado em terreiro de concreto, em camada de aproximadamente $10 \mathrm{~cm}$, sendo revolvido a cada 30 minutos. O período de pré-secagem durou seis dias. A partir do quinto dia de secagem, o café foi amontoado para facilitar os processos de homogeneização de seu teor de água e carregamento do secador.

Para a realização do teste, foram usados, concomitantemente, dois secadores rotativos da marca Pinhalense, com capacidade de $5.000 \mathrm{~kg}$ cada, com espessura da camada de café de 0,6 m e área de secagem de $4 \mathrm{~m}^{2}$. Cada secador foi equipado com uma fornalha de fogo indireto e um queimador da marca Ecoflam, modelo BLU-170. Uma adaptação em forma de Y foi usada para fazer o acoplamento da fornalha e do queimador em um mesmo conjunto ventilador-secador. A essa adaptação apresentava um registro para possibilitar o uso, independentemente da fornalha ou do queimador. As secagens foram conduzidas de maneira intermitente, pois à noite o secador era desligado, e a secagem era retomada na manhã seguinte.

As temperaturas do ar no plenum, da massa do café e do ar de exaustão, foram obtidas por meio de termopares tipo T situados a $210 \mathrm{~mm} ; 355 \mathrm{~mm} ; 500 \mathrm{~mm}$ e $775 \mathrm{~mm}$ da chapa perfurada do secador (Figura 1). Os termopares foram fixados dentro de tubos de aço instalados radialmente em três seções dos secadores.

O termopar localizado a $775 \mathrm{~mm}$ coincidia com o centro do plenum, representando, assim, a temperatura do ar no plenum. Os termopares localizados a $500 \mathrm{~mm}, 355 \mathrm{~mm}$ e $210 \mathrm{~mm}$ referiam-se a três diferentes pontos de temperaturas na profundidade, na direção radial da massa de grãos.

O secador foi dividido em três seções, numeradas a partir da entrada de ar, e cada seção numerada radialmente a partir do plenum (Figura 1). 


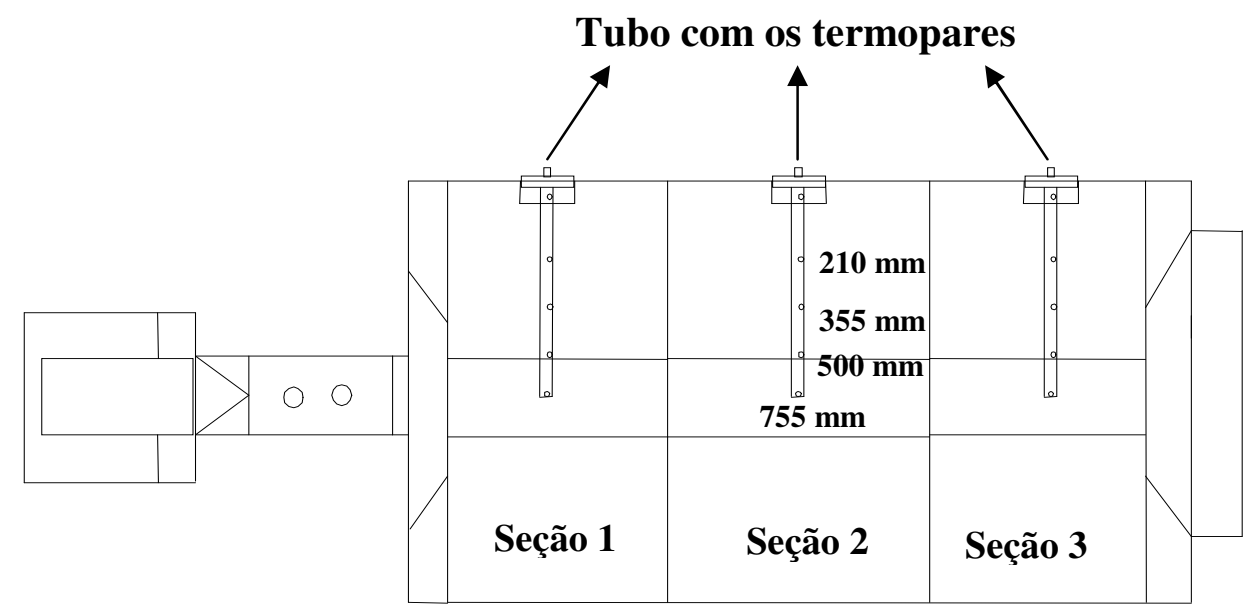

FIGURA 1. Corte transversal do secador indicando a disposição dos termopares em cada uma das três seções, na direção radial do secador.

Os cabos dos termopares foram passados por dentro do cano e conectados a indicadores de temperaturas fixados na parede externa do secador (Figura 2).

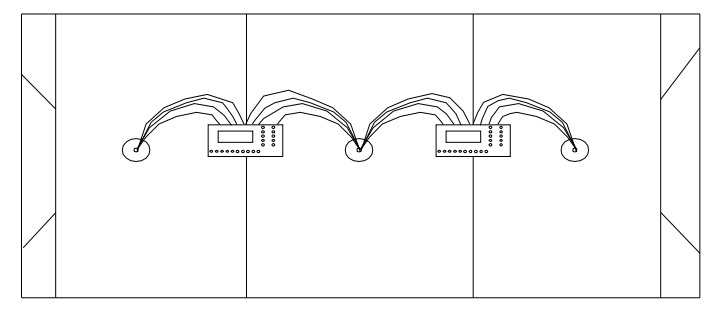

FIGURA 2. Vista frontal do secador evidenciando os indicadores e as conexões dos cabos dos termopares.

Os indicadores de temperatura, dois por secador, encontravam-se fixados por meio de um suporte confeccionado com cantoneiras. Cada indicador possuía entrada para dez termopares, e a alimentação foi feita por bateria recarregável de $12 \mathrm{~V}$, com autonomia de $24 \mathrm{~h}$, tempo suficiente para realizar as secagens.

As leituras de todas as temperaturas registradas no indicador foram feitas de meia em meia hora e anotadas em planilhas, sendo as temperaturas expressas em ${ }^{\circ} \mathrm{C}$.

As determinações de teor de água do café foram realizadas pelo método-padrão de estufa a $105^{ \pm} 3{ }^{\circ} \mathrm{C}$, usando-se duas amostras de aproximadamente $60 \mathrm{~g}$ (BRASIL, 1992).

Os resultados foram expressos em \% b.u. As amostras para a determinação do teor de água foram retiradas antes da secagem, durante a secagem em intervalos de duas horas e ao final da secagem. Foram realizadas amostragens em diferentes posições dentro da massa (Figura 3).

As amostras foram obtidas usando-se um calador projetado para retirar três amostras radialmente eqüidistantes (Figura 3 ).

Para encerramento da secagem, o teor de água do café, expresso em b.u., foi determinado pelo método de capacitância elétrica, usando-se o aparelho modelo G 800 da marca Gehole. 


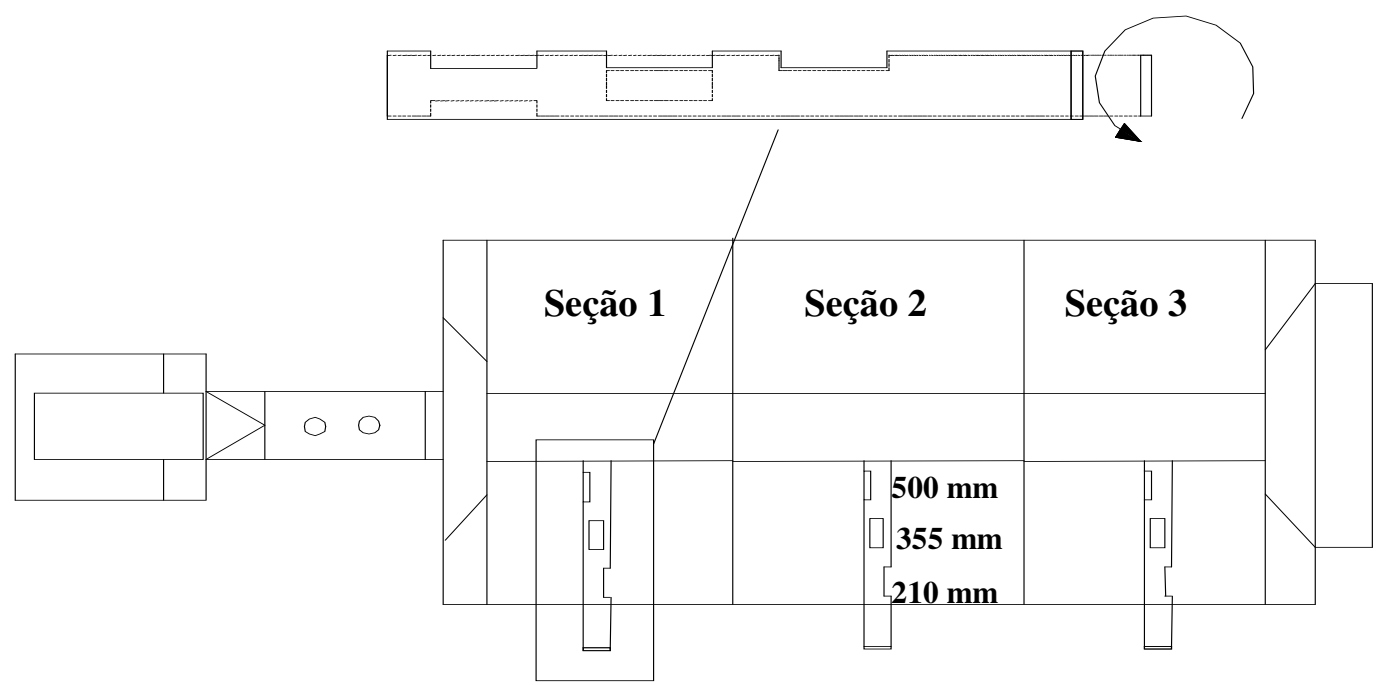

FIGURA 3. Distribuição e detalhes dos caladores com as respectivas numerações no secador e detalhe do calador.

\section{RESULTADOS E DISCUSSÃO}

As variações ocorridas na temperatura do ar do plenum, na temperatura do teor de água do café na direção radial, nas três seções do secador, nos testes de secagem usando-se como combustíveis GLP e lenha, encontram-se, respectivamente, nas Figuras 4 e 5.

Nota-se que os valores de temperatura no plenum apresentaram menor oscilação na secagem quando se usou GLP como combustível (Figura 4), comparativamente à secagem que usou lenha (Figura 5).

Enquanto na secagem que usou GLP como combustível o queimador era equipado com sistema de automação e controle, garantindo maior estabilidade da temperatura do ar na secagem utilizando lenha, o controle de temperatura era obtido a partir do fornecimento manual de lenha na fornalha. O princípio de funcionamento dos equipamentos usados para o aquecimento do ar também explica os valores máximos atingidos pela temperatura do ar no plenum, bem como o tempo necessário para o aquecimento e o resfriamento do ar.

$\mathrm{Na}$ secagem em que se utilizou lenha, além da temperatura máxima ter sido inferior à temperatura máxima na secagem em que se utilizou GLP como combustível, a elevação e a redução da temperatura foram lentas e graduais, atingindo valores de até $80{ }^{\circ} \mathrm{C}$, antes do repouso, e $89^{\circ} \mathrm{C}$ após nas seções 1 e 2 , e $71^{\circ} \mathrm{C}$ antes e $80^{\circ} \mathrm{C}$ após o repouso na seção 3 do secador (Figura 5).

$\mathrm{Na}$ secagem em que se utilizou GLP, as temperaturas máximas foram rapidamente alcançadas, atingindo valores de $90^{\circ} \mathrm{C}$ na seção $1 ; 85^{\circ} \mathrm{C}$ na seção 2 , e $75^{\circ} \mathrm{C}$ na seção 3 , antes do repouso, e $103^{\circ} \mathrm{C}$ na seção $1 ; 99^{\circ} \mathrm{C}$ na seção 2 , e $80^{\circ} \mathrm{C}$ na seção 3 , após o repouso (Figura 4).

Tanto na secagem que utilizou GLP como na secagem que utilizou lenha, a redução da temperatura do ar no plenum para valores inferiores a $60{ }^{\circ} \mathrm{C}$ ocorreu no momento em que o termômetro do secador indicou valor de $45^{\circ} \mathrm{C}$.

Observa-se que tanto as oscilações na temperatura como os valores máximos atingidos na massa seguiram as variações ocorridas no ar do plenum.

Dessa maneira, a temperatura da massa do café atingiu valores mais elevados na secagem que fez uso do GLP, sendo registrados valores de até $70^{\circ} \mathrm{C}$ na seção 2 do secador (Figura 4), valor médio de $58^{\circ} \mathrm{C}$ próximo ao plenum, $51^{\circ} \mathrm{C}$ no centro do secador e $45^{\circ} \mathrm{C}$ próximo à exaustão. Além disso, observa-se variação de temperatura de $15^{\circ}$ a $25^{\circ} \mathrm{C}$ na direção radial. Essa variação somente foi inferior a $5^{\circ} \mathrm{C}$ nas últimas horas de secagem, quando a temperatura do ar no plenum foi mantida em torno de $60^{\circ} \mathrm{C}$. 
Na secagem que fez uso de lenha (Figura 5), a temperatura máxima atingida pela massa de café foi de $68{ }^{\circ} \mathrm{C}$ na seção 2 do secador, e valores médios de $61{ }^{\circ} \mathrm{C}$ próximo ao plenum, $50{ }^{\circ} \mathrm{C}$ na metade da profundidade radial do secador e $45^{\circ} \mathrm{C}$ próximo à exaustão.

As variações de temperatura na direção radial foram menores, variando entre 5 e $15^{\circ} \mathrm{C}$, semelhante ao que foi observado na secagem que fez uso de GLP como fonte de aquecimento do ar de secagem, na qual o gradiente foi inferior a $5{ }^{\circ} \mathrm{C}$, quando a temperatura do ar no plenum foi mantida abaixo de $60^{\circ} \mathrm{C}$.
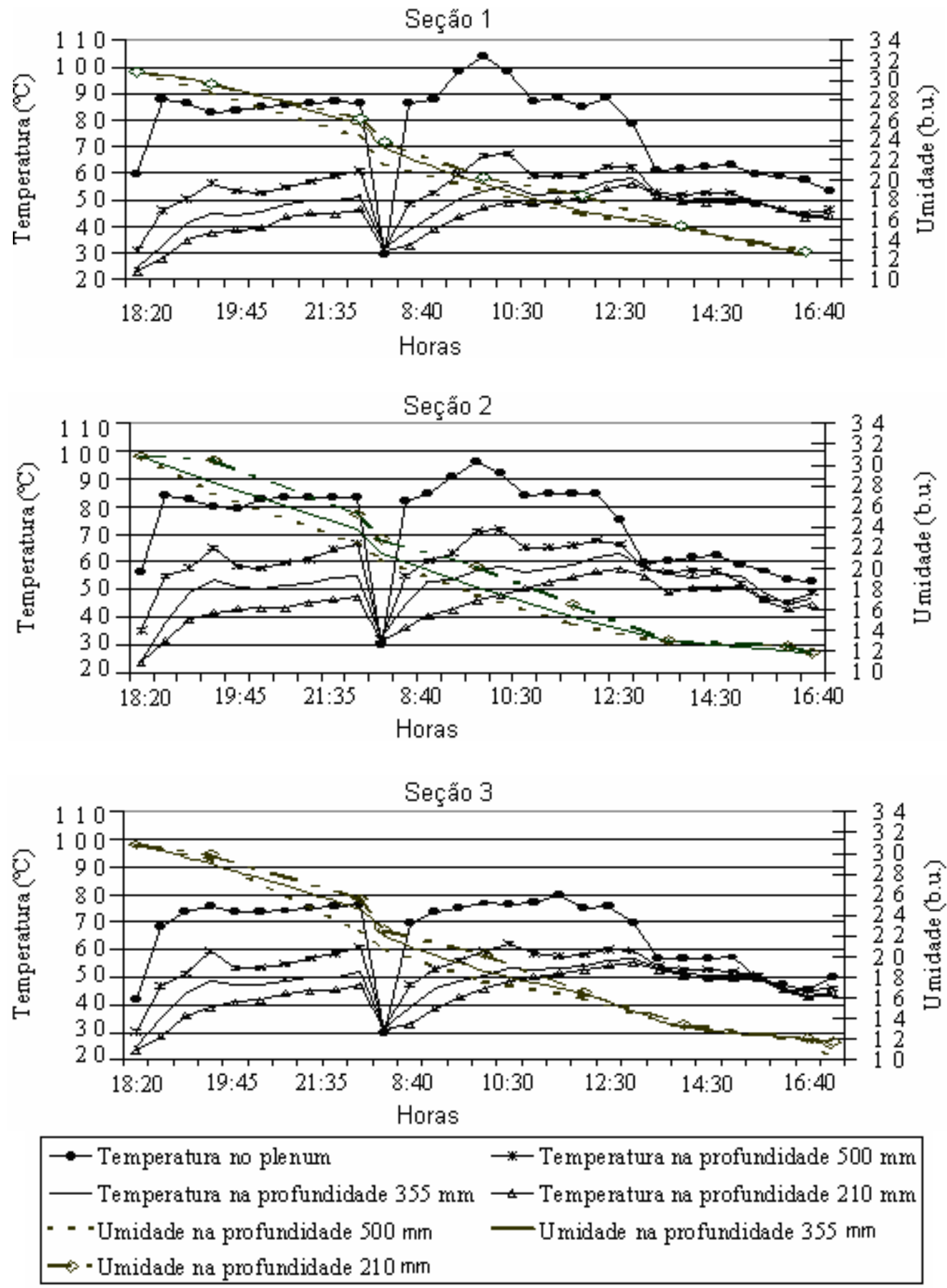

FIGURA 4. Variações de temperatura do ar do plenum, na temperatura do teor de água da massa de café na direção radial, nas três seções do secador, para a secagem em que se usou GLP como fonte de aquecimento. 

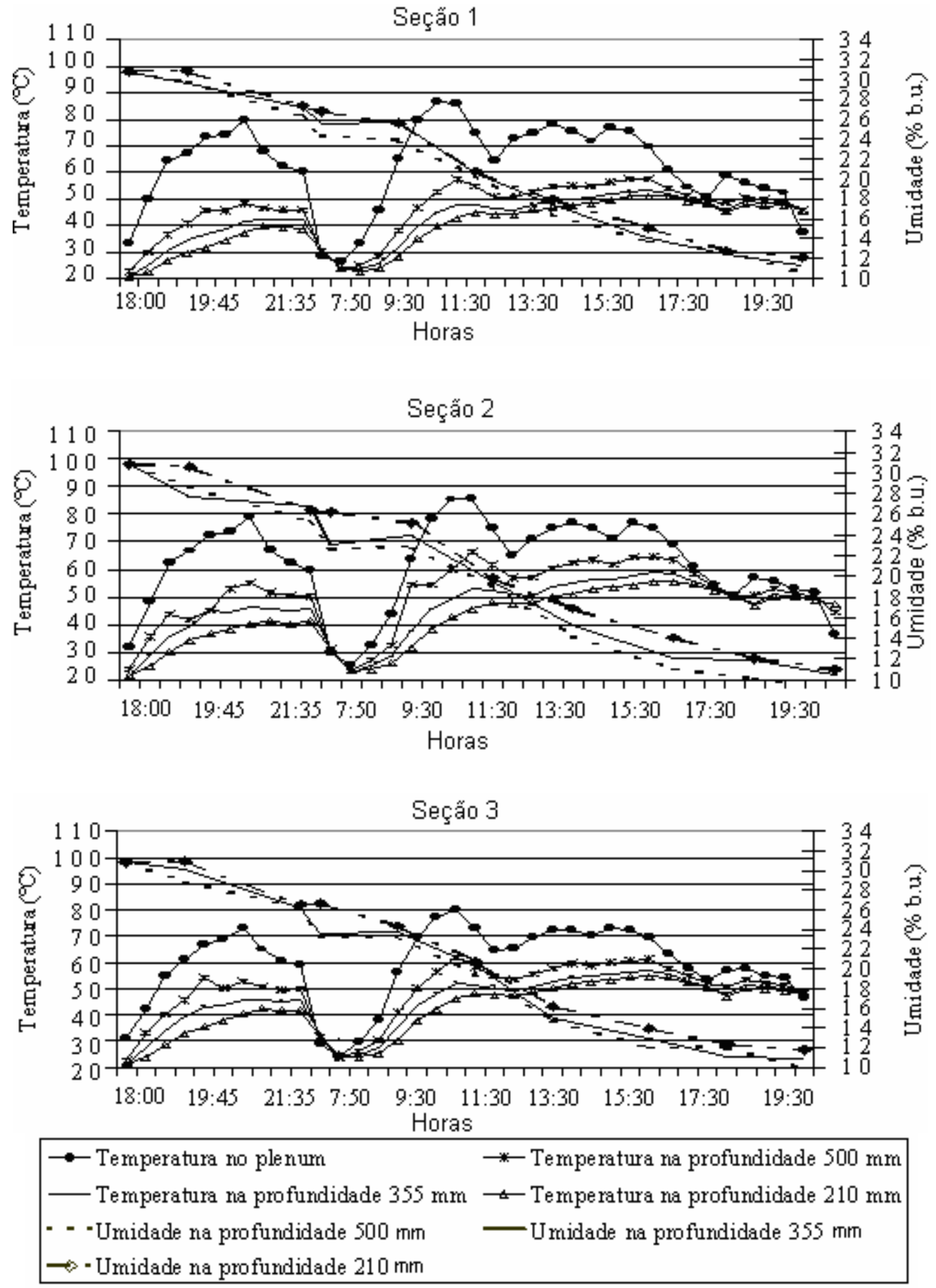

FIGURA 5. Variações de temperatura do ar do plenum, na temperatura do teor de água da massa de café na direção radial, nas três seções do secador, para a secagem em que se usou lenha como fonte de aquecimento.

Essas observações foram consideradas de grande relevância, pois, durante toda a secagem, a temperatura registrada no termômetro bimetálico do secador não ultrapassou o valor de $45^{\circ} \mathrm{C}$. Entretanto, os valores observados na massa do café foram bem superiores a $45^{\circ} \mathrm{C}$, contrariando as recomendações técnicas para secagem.

Conforme pode ser observado nas Figuras 4 e 5, logo após o início da secagem, formou-se um gradiente de teor de água de até três pontos percentuais, sendo mais acentuado na seção 2 do secador. 
Ao longo de toda a secagem, independentemente do tipo de combustível, os maiores gradientes de teor de água do produto na direção radial ocorreram na seção 2 dos secadores. Nessa seção, foram observados valores maiores de pressão estática no plenum (Secção $1=1,5 \mathrm{~mm}$; Seção $2=6,5 \mathrm{~mm}$ e Seção $3=4 \mathrm{~mm}$ ), indicando desuniformidade de distribuição do ar.

As variações na temperatura e no teor de água da massa de café, na direção longitudinal, em três profundidades $(210 \mathrm{~mm} ; 355 \mathrm{~mm}, 510 \mathrm{~mm})$, no primeiro teste que comparou GLP e lenha com combustíveis, são apresentadas, respectivamente, nas Figuras 6 e 7.
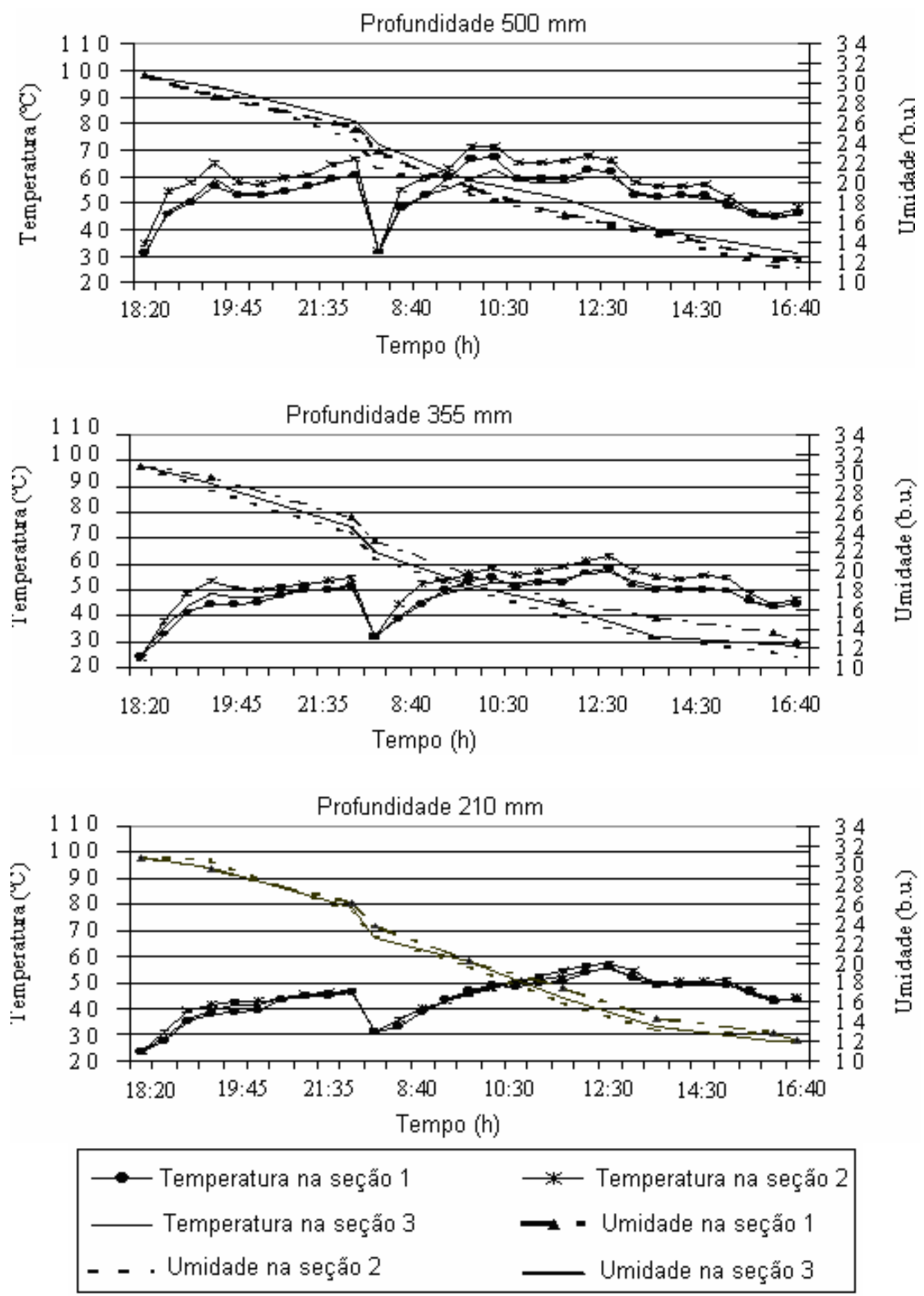

FIGURA 6. Variações da temperatura e do teor de água da massa de café, na direção longitudinal, nas três seções do secador, para a secagem em que se usou GLP como fonte de aquecimento. 

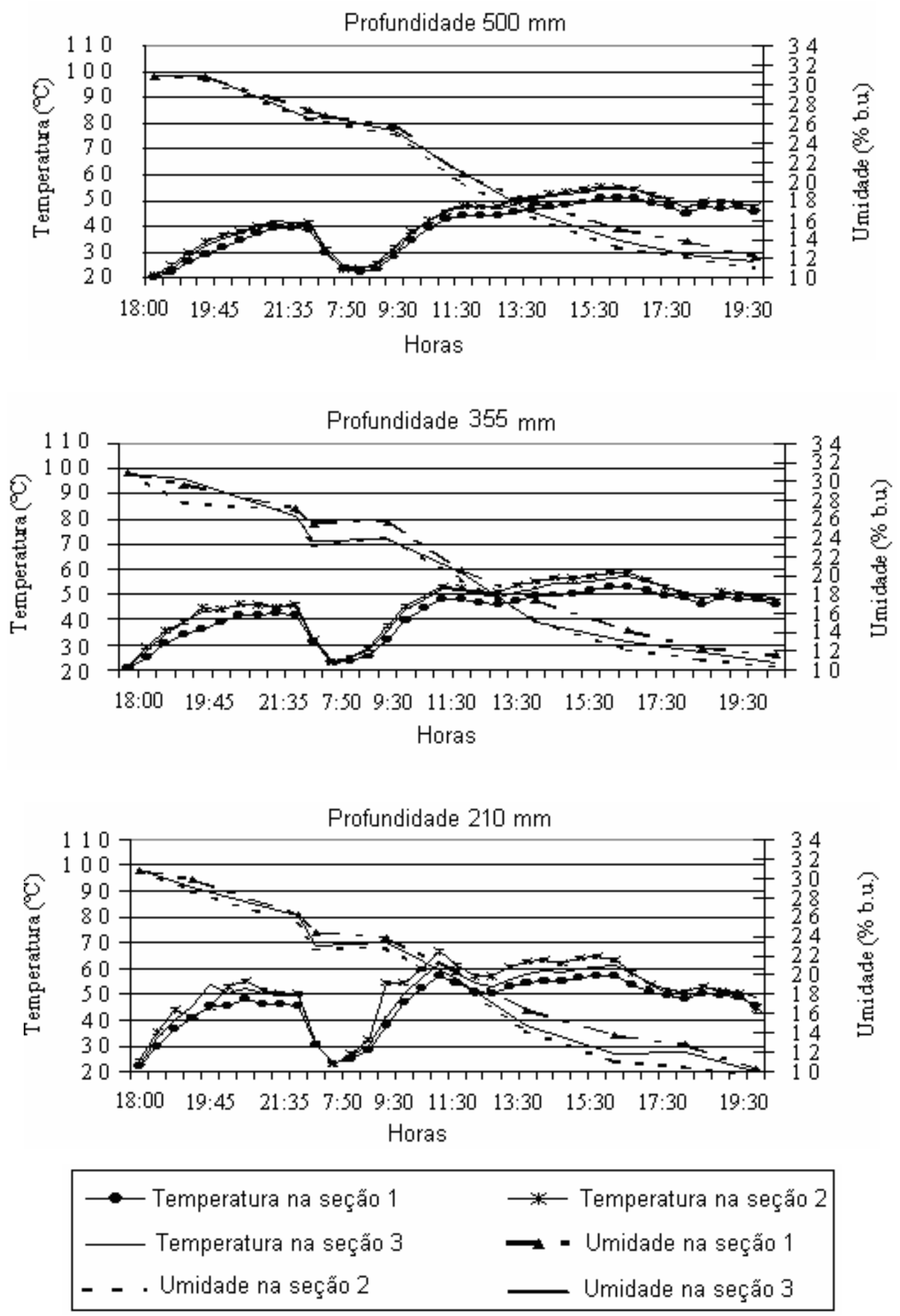

FIGURA 7. Variações da temperatura e do teor de água da massa de café, na direção longitudinal, nas três seções do secador, para a secagem em que se usou lenha como fonte de aquecimento.

De maneira geral, o gradiente de temperatura observado longitudinalmente na massa de café foi bem menor do que na direção radial. As maiores variações ocorreram próximo ao plenum (500 $\mathrm{mm}$ de profundidade), não sendo observado gradiente de temperatura próximo à exaustão do ar (210 $\mathrm{mm}$ de profundidade). O gradiente de temperatura, observado longitudinalmente, ocorreu como conseqüência da desuniformidade na distribuição do ar, conforme discutido anteriormente. 
Quanto ao gradiente de umidade, observa-se que, nas profundidades $500 \mathrm{~mm}$ e $355 \mathrm{~mm}$, mesmo no final da secagem, independentemente do combustível usado, ocorreram diferenças de até dois pontos percentuais. Já na profundidade de $210 \mathrm{~mm}$, próximo à exaustão do ar, não se observou gradiente de umidade. Esse fato possivelmente aconteceu tanto por não ter ocorrido gradiente de temperatura, como também por uma provável movimentação longitudinal do café mais eficiente.

\section{CONCLUSÕES}

As variações de temperatura observadas longitudinalmente na massa de café foram menores do que na direção radial.

O uso do GLP como combustível resulta em maiores gradientes de temperatura, porém menores variações de teor de água.

Os maiores gradientes de teor de água do produto, na direção radial, ocorreram na seção central do secador.

Na seção intermediária do secador, ocorreram maiores valores de pressão estática no plenum.

\section{REFERÊNCIAS}

BRASIL. Ministério da Agricultura e Reforma Agrária. Secretaria Nacional de Defesa Agropecuária. Regras de análise de sementes. Brasília, 1992. 365 p.

CASTRO, L.H. Efeito do despolpamento, em secador de leito fixo sob alta temperatura, no consumo de energia e na qualidade do café (Coffea arabica L.). 1991. 61 f. Dissertação (Mestrado em Secagem e Armazenamento) - Universidade Federal de Viçosa, Viçosa - MG, 1991.

GIRANDA, R.N. Aspectos qualitativos de cafés submetidos a diferentes processos de secagem. 1998. 98 f. Dissertação (Mestrado em Ciência dos Alimentos) - Universidade Federal de Lavras, Lavras - MG, 1998.

LACERDA FILHO, A.F. Avaliação de diferentes sistemas de secagem e suas influências na qualidade do café (Coffea arabica L.). 1986. 136 f. Dissertação (Mestrado em Secagem e Armazenamento) - Universidade Federal de Viçosa, Viçosa - MG, 1986.

OCTAVIANI, J.C. Secagem de café cereja descascado desmucilado com a utilização de GLP. 2000. 120 f. Tese (Doutorado em Armazenamento e Pós-Colheita de Grãos) - Universidade Estadual de Campinas, Campinas, 2000.

REINATO, C.H.R.; BORÉM, F.M.; PEREIRA, R.G. Avaliação de sistemas de secagem de café em propriedades agrícolas do sul de Minas Gerais. In: CONGRESSO BRASILEIRO DE PESQUISAS CAFEEIRAS, 27., 2001, Uberaba. Anais.... Rio de Janeiro: MA/PROCAFÉ, 2001. p.384-6.

SILVA, J. de S.; LACERDA FILHO, A.F. de; BERBERT, P.A. Secagem e armazenagem de produtos agrícolas. In: SILVA, J. de S. Secagem e armazenagem de produtos agrícolas. Viçosa: UFV, 2000. p.395-467. 